\title{
A sala dos intervalos no cinema de Fernando Solanas
}

\author{
Miguel Pereira (Miguel Serpa Pereira)1
}

\begin{abstract}
RESUMO
A partir do conceito de intervalo de Dziga Vertov, recuperado por Gilles Deleuze, discute-se a possibilidade de sua presença no cinema de Fernando Solanas, em especial nos filmes "La hora de los hornos" (1966/ 68) e "Tangos, exilio de Gardel" (1985), tentando mostrar como a interferéncia do autor cria um estranhamento nas fronteiras da linguagem e amplia o sentido de seu trabalho, possibilitando ao espectador novas leituras dos filmes.
\end{abstract}

Palavras-chave: Ferando Solanas, Dziga Vertov, Intervalo, Teorias do Cinema

\section{ABSTRACT}

From the concept of interval by Dziga Vertov, recuperated by Gilles Deleuze, we discuss the possiblitiy of its presence in the cinema of Fernando Solanas, specially in the films "La hora de los hornos" (1966/ 1968) and "Tangos, exilio de Gardel" (1985), trying to show how the author's intervention creates a strange finding on the borders of language and amplifies the sense of his work, providing new interpretations for the films to the viewers.

Key words: Ferando Solanas, Dziga Vertov, Interval, Theorys of the cinema 


\section{Introdução}

Este texto pretende discutir a possibilidade de se verificar em dois filmes de Fernando Solanas, "La hora de los hornos" (1966/68) e "Tangos, exílio de Gardel" (1985), a teoria do intervalo, conceito criado por Dziga Vertov e contemporaneamente resgatado por Gilles Deleuze. O interesse nesta espécie de aplicação de uma teoria é mostrar como o cinema provoca no espectador um dirigismo de atenção e ao mesmo tempo uma liberdade interpretativa que pode não estar presente na intenção direta do realizador. Por se tratar de dois realizadores visceralmente envolvidos com as questões políticas de seu tempo, a hipótese é que Solanas assumiu o método vertoviano em seus trabalhos, especialmente em "La horas de los hornos".

Na verdade, Solanas começou a coletar e a filmar cenas do cotidiano argentino, desde 1964, pensando em fazer um filme que fosse uma espécie de "ensaio histórico-sociológico sobre a Argentina" (CAETANO, 1997:61). Junto com Octavio Getino, o roteirista do filme, Solanas estava diretamente contaminado pelo cinema novo brasileiro, especialmente por "Maioria absoluta" (1964), de Leon Hirszman, mas também por "Tiré dié"(1959/60), do seu conterrâneo Fernando Birri, e "Now" (1965), do cubano Santiago Alvarez. Aliás, o título inicialmente pensado era "Notas e testemunhos sobre o neocolonialismo, a violência e a libertação" que virou subtítulo. "La hora de los hornos" veio dos Diários de Guerrilha de Che Guevara onde está citada essa

128 expressão do José Marti. Mas, o próprio Solanas se refere à influência de Dziga Vertov no que diz respeito à utilização, no filme, de cartazes, textos, legendas e intervalos destinados à conscientização dos espectadores através de debates. (CAETANO, 1997: 61).

Também em "Tangos, exílio de Gardel" a questão é a política, aqui abordada do ponto de vista dos exilados e do preconceito colonial, presente na "acolhedora" França dos anos 60 e 70 . Esse viés colonialista aparece na cena em que os críticos e funcionários que acabaram de assistir à montagem da "Tanguédia", peça musical montada por um grupo de exilados em Paris, se manifestam perplexos, criticando a "descontinuidade" da obra, entre outros problemas, chegando a frase dita por uma senhora presente: "Nós franceses amamos os latino-americanos somente enquanto eles realizam o que nós esperamos deles" (LABAKI e CEREGHNNO, 1993:58). Também a narrativa de "Tangos, exílio de Gardel" é construída no sentido de abrir-se aos intervalos vertovianos.

\section{Vertov e Solanas}

Dziga Vertov elaborou a sua teoria do cinema a partir de uma prática inserida num contexto revolucionário. Este é o seu limite, mas é também a sua grandeza. Ao refletir sobre a própria produção, construía também um 
pensamento original que o distinguia dos contemporâneos. Sua radicalidade era fruto de um desejo de repensar o mundo a partir de um modelo diferente de sociedade, de onde emergiria um homem novo. Fundamentava-se assim naquilo que se convencionou chamar de "construtivismo" no campo da arte e de "revolução social" no âmbito da sociedade. Tratava-se, portanto, de um estado em processo de desenvolvimento com o objetivo de chegar ao comunismo. Seu interesse era lutar para encontrar um modelo ideal de vida social, uma vez que a revolução de 1917 fora vitoriosa e estava em fase de implantação. Era pois o momento de construir a nova sociedade.

Por isso, buscava libertar-se de todas as limitações que o processo cinematográfico tinha estabelecido como norma e padrões narrativos. Esta ânsia de quebrar com o estabelecido tem origem numa formação estética fundamentada nos princípios da música. Vertov foi estudante de música antes de se tornar cineasta, passando também pelas letras. Mas, foi na música que buscou as principais equivalências necessárias para entender a forma cinematográfica. Um dos elementos centrais de sua teia conceitual é a idéia do intervalo. Um conceito, como tudo que nos deixou, pouco desenvolvido, mas com poderosas intuições. $E$, sem dúvida, ancorado no seu sentido musical.

Fernando Solanas, cineasta argentino contemporâneo, também vive a paixão da luta pela mudança social e política de seu país. Ingressou até mesmo na via institucional como deputado nacional, entre 1993 e 1997, e também candidato à Presidência da República, em 1995. Como Vertov, estudou música, e também direito, artes plásticas e teatro. Antes de se fixar no cinema, trabalhou no mercado publicitário dirigindo centenas de filmes. Embora não se possa falar de um mercado publicitário na época de Vertov, ele, de certa maneira, também fez a publicidade da Revolução Russa com seus filmes. Mas, não pretendo aqui fazer uma comparação das duas trajetórias político-artísticas, apenas sublinhar a noção de intervalo que parece ser comum a ambos, proposta como uma singularidade narrativa que certamente se encontra também outros cineastas e filmes.

\section{$O$ intervalo segundo Vertov}

Mais contemporaneamente, quem trouxe para reflexão cinematográfica a questão do intervalo no cinema foi Gilles Deleuze em sua obra $A$ imagemmovimento, de 1983. Também Georges Sadoul, no livro sobre Vertov, destaca o conceito de intervalo no cinema do cineasta russo. $O$ mesmo se pode falar de Jean Mitry, para ficar apcnas em dois clássicos da teoria cinematográfica.

Sadoul (1973) pergunta:

"Para Vertov, qual é o sentido da palavra intervalo que passou do francês para o russo com o mesmo tríplice significado? : 1) espaço ou distância de um lugar ao outro; 2) distância de um tempo ao outro; 3) 
diferença de altura entre sons. Neste último sentido, trata-se de uma relação de frequência. Um modo, uma escala, um acorde se definem por intervalos que existem entre os sons que os compõem. Vertov dava à palavra intervalo, em primeiro lugar, o seu sentido musical, tal the ensinaram no conservatório de música. Esta definição o conduziu a uma quarta, puramente cinematográfica: colagem, enlace, ligação, concordância entre dois pedaços de filme, quer dizer, a passagem de uma tomada (de um elemento filmico) à outra. Essa passagem supõe, na maioria das vezes, uma mudança de lugar e uma mudança de tempo" (Sadoul: 1973: 74)

Para Vertov, a relação entre uma tomada e outra é que constrói o espaço e o tempo no filme que se diferenciam do espaço e do tempo reais. Por isso criou a imagem de uma casa com doze paredes captadas em diferentes partes do mundo, que ele chama de "sala dos intervalos", que não existe na realidade, mas existe através do filme e de sua montagem. Quer dizer, Vertov não está apenas interessado na relação de imagens próximas, mas também das distantes que participam do mesmo movimento filmico. Assim, a montagem não é apenas a junção de imagens, mas a sua relação com todas a imagens que estão no filme, depois de montado. Isto é, os intervalos de sentido que podem ligar imagens distantes, como na música, por exemplo, um intervalo de quarta aumentada que causa um estranhamento ao ouvido acostumado às harmonias mais convencionais. Às vezes, intervalos menores criam dissonâncias que também podem provocar esse mesmo estranhamento e algum nivel de atenção mais dirigida. Com isso, Vertov pensava construir um edificio cinematográfico em que as ligações atravessariam todos os espaços e tempos do mundo imaginário.

É nesse contexto que Deleuze retoma Vertov para mostrar, entre outras percepções:

"a irređutibilidade da experiência da percepção natural faz da ligação entre Bergson e o cinema uma aliança de fato. O universo material das imagens-movimento é, para Deleuze, estritamente falando, um metacinema: aquele que permite ir além das posiçøes explícitas de Bergson sobre o cinema e estabelecer a comparação em um outro nível. O cinema em și é também irredutível ao modelo da percepção natural. A mobilidade da câmera, as variação dos ângulos e dos enquadramentos re-introduzem sempre zonas descentradas e desenquadradas não importando a percepção dos sujeitos. $O$ cinema tem uma estreita ligação com o primeiro regime da imagem-movimento, isto é, o da variação universal e da percepção total e objetiva. Ele pode voltar sempre àquilo que torna a experiência propriamente humana, juntando a percepção à matéria, o em-si da imagem". (MARRATI, 2003: 51) 
Assim, a diferença marcada entre a experiência da percepção natural e a da imagem faz com que o conceito de intervalo amplie a capacidade perceptiva do ser humano propondo um regime universal de relações. $O$ artifice desse processo é exatamente a imagem-movimento, ou o em-si da imagem, como uma espécie de natureza do cinema enquanto forma perceptiva por um sujeito qualquer. É nesse meta-lugar que o cinema ocupa um espaço sem fronteiras, portanto universal em potência subjetiva. Melhor dizendo, enquanto o estado cerebral é linear, narrativo e lógico em relação à causa e o efeito, o cinema-olho de Vertov e sua teoria do intervalo estão mais próximos da percepção direta ou da "percepção pura", isto é, não linear, sem limites lógicos no espaço-tempo. Isto porque o dispositivo cinematográfico permite essa ampliação universal da percepção, saindo da lógica cerebral para espaços que se relacionam através de intervalos contidos no em-si das imagens em movimento. É exatamente este processo que faz com os intervalos contidos nos movimentos possam atrair imagens distantes e criar sentido entre elas. Por isso é que Vertov buscava modelar a nova sociedade e o novo homem através de uma nova arte que deveria negar os padrões estabelecidos, quer técnicos, quer narrativos, ou mesmo imagéticos.

Segundo Deleuze, a originalidade de Vertov está exatamente na concepção de intervalo não como o lugar em que separam duas imagens consecutivas, mas aquele que estabelece uma relação entre duas imagens distantes "incomensuráveis do ponto de vista da percepção humana".

"O intervalo entre dois movimentos desenha um lugar vazio que prefigura o sujeito humano enquanto se apropria da percepção. Mas, o mais importante, para Vertov, vai ser restituir os intervalos à matéria. É o sentido da montagem, e da 'teoria dos intervalos', mais profunda do que a do movimento. O intervalo já não será o que separa uma reação da ação sofrida, o que mede $a$ incomensurabilidade e imprevisibilidade da reação, mas, pelo contrário, o que, uma ação sendo dada num ponto do universo, encontrará a reação apropriada num outro ponto qualquer e por mais distante que esteja ("encontrar na vida a resposta ao assunto tratado, a resultante entre milhões de fatos que apresentam uma relação com o assunto') ... o intervalo não marca apenas um hiato que se cava, uma distância entre duas imagens consecutivas, mas pelo contrário uma colocação de duas imagens longínquas. $E$, por outro lado, o cinema não podia correr assim de uma extremidade à outra do universo se não dispusesse de um agente capaz fazer concorrer todas as partes: o que Vertov retirou ao espírito, isto é, o poder de um todo que não pára de se fazer, vai agora passar ao correlato da matéria, das suas variações e interações. Com efeito, o agenciamento maquinico das coisas, das imagens em si, tem por correlato um agenciamento de enunciação coletivo. Já no mudo, Vertov fazia do intertítulo um uso original em que 
a palavra formava um bloco com a imagem, uma espécie de ideograma. São dois aspectos fundamentais do agenciamento: a máquina de imagens é inseparável de um tipo de enunciados, de uma enunciação propriamente cinematográfica." (DELEUZE, 2004: 118)

O coletivo a que se refere Deleuze é a consciência soviética da realidade, "da decifração comunista da realidade". É essa visão construtiva de um novo mundo e de um novo homem. Nåo se trata, portanto, de "reproduzir o visível, mas tornar visivel", numa cara citação de Deleuze a Paul Klee, uma vez que o processo está ainda em andamento, ou melhor, em movimento. No fundo, também esta é a crença numa mudança de acordo com um ideal a ser conquistado. Um modelo o ser seguido. Enfim, uma direção, um projeto, uma utopia.

É também dentro de um contexto semelhante que o cinema de Solanas aparece e se consolida. Seu ideal é também a mudança social e quer colocar o cinema a serviço dessa idéia. Mas, o ponto de partida de ambos era bem diferente. Se Vertov participava de um movimento vitorioso, a Revolução de 1917, Solanas buscava a libertação de um regime opressor, injusto e neocolonial que vigorava em seu país há séculos. Por isso, seu cinema é propositivo, educativo, construtor, metodológico, experimental, controlador, libertário, enfim. Pois é na dualidade comunicar e deixar comunicar que tentou navegar Fernando Solanas nos filmes "La hora de los hornos" e "Tangos,

132 exílio de Gardel".

\section{A hora e oxílio}

Essas duas palavras dizem que uma passou e a outra está em andamento. A gestação de um momento que ainda não alcançou seus objetivos, está no forno, cozinhando, é um movimento registrado pela história. A hora passou e não deu frutos. Deu no exílio. Um talvez seja a causa e o outro a consequêencia. $O$ exilio hoje já perdeu parte de sua conotação política e está mais próximo de uma vocação empreendedora de uma vida melhor, sem fronteiras. Aberturas desejadas e fechamentos provocados desenham as relaç̃es entre os povos e as culturas atuais. Se a Europa e os Estados Unidos se abriram aos emigrantes, hoje se fecham em suas fronteiras geográficas, econômicas e políticas. Não querem saber de imigrantes. Os que já estão em seus territórios são suficientes para os serviços de que precisam. Da tolerância à intolerância $o$ espaço de tempo foi bem curto. Talvez meio século. $O$ que vigora hoje é o controle, o medo do terrorismo, a desconfiança e preconceito. Dos vistos negados sem qualquer fundamento à prisão arbitrária de "suspeitos" identificados apenas pelo sobrenome, enfim, a realidade do estrangeiro mudou radicalmente nos dois últimos decênios. 
Visto por este ângulo, "Tangos, o exilio de Gardel" é quase um filme ingênuo. Só não o é pela sutileza que Solanas colocou na cena antes aqui descrita. O sinal está no filme como uma espécie de sentimento vivido pelo colonizado diante do colonizador. Esse sentimento de inferioridade de que fala Frantz Fanon continua rondando os modelos que assumimos de avaliação de nós mesmos. Esse sentimento se estende a todos os setores da vida social, inclusive à acadêmica. Vale mais publicar fora do que dentro do país. Enfim, são linhas de conduta que podem até ter sua razão de ser e por isso justificadas, mas indubitavelmente, são destruidoras de uma alma própria. Infclizmente, a antropofagia, pregada pelos modernistas brasileiros, ainda não se entranhou no tecido social. É coisa de elites intelectuais que fazem belos discursos sem atingir o sentimento mais interior do homem enquanto ser circunscrito a viver numa cultura e num território.

"La hora de los hornos" se situa num patamar cultural que não admite negociaç̃oes. Sua verdade é transparente. Todos os recursos expressivos são usados nesse sentido. É um panfleto, como o próprio Solanas admite. Não qualquer panfleto. "O filme foi lançado em 1968 ... Creio que sobreviveu ao tempo, por trata-se de um panfleto concebido como gênero narrativo e não como um panfleto qualquer, sem valor estético" (CAETANO, 1997: 61). Ou, na expressão de Marco Bellochio, "não é um filme, é um fusil". Poucas vezes foi exibida a sua versão completa, que dura $4 \mathrm{~h} 44 \mathrm{~m}$ (quatro horas e quarenta e quatro minutos). Sua apresentação no Festival de Pesaro, em 1968 foi não apenas consagradora. $O$ filme foi ovacionado e Solanas e Getino carregados por uma multidão que tomou conta da praça, dando-se, logo a seguir, um conflito de correntes ideológicas diferentes que terminou com a prisão de muitas gente, inclusive cineastas, entre eles, o nosso Paulo César Saraceni. Parte desses aplausos deve-se ao final da primeira parte, intitulada "Nacionalismo e violência", em que aparece aquela famosa fotografia do rosto do Che Guevara morto, de olhos abertos, que fica na tela por mais de quatro minutos, ao som de um ritmo marcadamente tocado em instrumentos de percussão. Mas, na Argentina o filme foi proibido em 1969. Apesar disso, foi exibido clandestinamente até 1973, tornando-se um indiscutível sucesso do cinema alternativo. Em algumas situações, os promotores das sessões corriam sérios risco de vida por causa da repressão política. Hoje "La hora de los hornos" é considerado um clássico do documentário político mundial.

Para entender as intenções estéticas do cineasta, cito aqui um parágrafo de Solanas por Solanas:

"Quando era jovem e ia ao cinema, me perguntava: 'O que me lembro do filme que acabei de ver?'. Muitas vezes lembrava-se de uma ou duas sequências, até brevíssimas. Recordo-me de um filme de Luis Buñuel, "Diário de uma camareira", com Jeanne Moreau. Um ato de violência sexual era o que despertara o meu interesse, uma imagem 
muito tenebrosa, com uma lesma subindo entre as pernas abertas da mulher. Uma extraordinária visão, poética e ao mesmo tempo violenta" (LABAKI e CEREGHINO, 1993: 35).

Se os modelos poéticos ele os retirou das influências buñuelescas, entre elas o documentário "las Hurdes", de 1932, a construçã̀o de suas narrativas foram inspiradas no cinema clássico soviético e nas formas que durante anos exercitou como profissional do cinema publicitário. Mas, "La hora de los hornos" constrói sua narrativa sob a inspiração também de Dziga Vertov. No que diz respeito especificamente à teoria dos intervalos, pode-se associar por exemplo a seqüência do leilão do gado com a seqüuência do cemitério da Recoleta. Se na primeira o que está em jogo é a caracterização de uma burguesia nacional ligada ao capital estrangeiro, na segunda os monumentos mortuários, mostrados ao som de uma ópera, representam essa mesma burguesia no estado de petrificação. Ficam apenas as imagens-símbolo de uma classe abastada que jaz petrificada em sua arrogância post-mortem. A superficialidade dessa mesma classe que frequienta os nobres salões das universidades em disputas telúricas inúteis, assim como os lançamentos de livros alinhados com 0 imperialismo, formam um crescendo emotivo que leva o espectador ao ódio a esse tipo de gente. São elementos que se associam por indução a partir da relação que se estabelece entre as diversas imagens que, de certo modo, se atraem no movimento do filme. O quadro não é composto numa ordem de

134 raciocínio lógico elementar. Mas, pela distância entre essas imagens intercaladas a outras que realizam o contraste com essas, como a situação social do povo argentino entregue à miséria e ao desamparo.

Numa outra linha de relacionamento, as diversas posturas políticas que a história argentina assumiu ao longo dos séculos. Nitidamente, aparece o primeiro empréstimo feito ao banco inglês como gerador de um dependência permanente da nação aos interesses da metrópole. A Argentina exportava a matéria prima e importava os manufaturados. Nessa relação, perdia seu poder de barganha e ficava cada vez mais dependente do capital externo. Também este quadro é composto pos espaços distantes que vão construindo na mente do espectador um sentido de revolta. A dramaturgia do documentário é mesmo para agredir, chocar, fazer pensar. Por outro lado, a liberdade de criar sentido permanece em aberto, e mais que isso, didaticamente, o filme abre espaço para a consciência grupal. Na segunda parte de "La hora de los hornos", a imagem preta e uma locução incitam os espectadores a debater, com o monitor ou animador presente à sessão, o que foi visto até aquele momento ou o que está mais próximo da visão deles. Neste caso é um intervalo fisico no filme, cuja projeção pode mesmo parar e ser retomada um pouco mais adiante. Esse exercício foi realizado em inúmeras sessões clandestinas em toda a Argentina. Neste caso, o filme virava um instrumento revolucionário de grande impacto emocional. Sua épica era também a sua didática. Esta aura de um filme 
clandestino a serviço de uma causa justa fez dele uma espécie de mito na história do cinema mundial.

Solanas retoma a mesma épica no seu último trabalho "Memória do saqueio" que se ocupa não mais do neo-colonialismo dos anos 60 , mas do atual neo-liberalismo que também está exaurindo as riquezas dos paises periféricos. Sob a capa da globalização, Solnas mostra o drástico empobrecimento sofrido pelo povo argentino nas últimas décadas. O massacre, como foi mostrado em "La hora de los hornos", continua, sem intervalos. A realidade é mais forte do que a fantasia. Esta alimenta mal e pouco a cidadania portenha. O sonho é um pouco do que Solanas narra em "Tangos, o exilio da Gardel".

Este filme, iluminado pela obsessão de continuar argentino mesmo no exílio, é um primor de lugares escorregadios, de fossos narrativos, de intervalos que levam a surpreendentes associações. $O$ passado, configurado na visita a uma espécie de museu de um dos fundadores da nacionalidade argentina, e o presente, através de uma manifestação pública exigindo explicações a respeito dos desaparecidos e a queda da ditadura, são elementos imagéticos que se ligam por associações previstas numa montagem criativa e ainda assim livre para que cada espectador possa construir o seu próprio sentido das imagens. Intervalos distantes ou próximos, as metáforas da pátria humilhada se espalham pelo filme inteiro. Das encenações da "Tanguédia" às posições políticas explícitas de alguns personagens, o sentimento do exílio aguça o amor pela terra de origem. "Tangos, exílio da Gardel" é também um panfleto político que leva ao inconformismo da situação vivida.

\section{Conclusão}

O que caracteriza o cinema de Fernando Solanas é o seu incorruptível combate político. Ele respira e vive, com todo o ardor de sua alma generosa, a possibilidade da mudança, a esperança de que dias melhores chegarão para todos os seus compatriotas e também para toda a América Latina. É um homem de fé e um cineasta talentoso. Sua coerência é espantosa, num mundo caracterizado pela falta de princípios e perspectivas. Vive-se, a cada momento, as surpresas de que o pior ainda não veio, pois, parece que cada dia que passa algo mais terrivel ainda vai acontecer. É o desalento corroendo os espíritos. Mas, contra tudo isso, Solanas empunha sua arte e resiste. Sua retórica impressiona e também nos anima, nos sentido de nos dar ânimo, senão a outros, pelos menos a mim. Obrigado Solanas!

\section{Referências bibliográficas}

AUMONT, Jacques. As Teorias dos Cineasta. São Paulo: Papirus, 2004 AVELLAR, José Carlos. A Ponte Clandestina. Teorias de Cinema na América Latina. 


\section{Contracampo}

São Paulo: Edusp/34, 1995

CAETANO, Maria do Rosário. Cineastas Latino-americanos. São Paulo: Estação Liberdade, 1997

COMOLLI, Jean-Louis. Filmar para ver. Escritos de Teoria y Critica de Cine. Buenos Aires: Simurg, 2002

DELEUZE, Gilles. A Imagem-movimento. Cinema 1. Lisboa: Assírio e Alvim, 2004

GRANJA, Vasco. Dziga Vertov. Lisboa: Horizonte, 1981

KRIGER, Clara e PORTELA, Alejandra. Diccionario de Realizadores. Buenos Aires: Jilguero, 1997

LABAKI, Amir e CEREGHINO, Mario J. Solanas por Solanas. São Paulo: Iluminuras, 1993

MANRUPE, Raúl e PORTELA, Maria Alejandra. Un Diccionario de Files Argentinos. Buenos Aires: Corregidor, 2001

MARRATI, Paola. Gilles Deleuze: Cinéma e Philosophie. Paris: PUF, 2003

SADOUL, Georges. El Cine de Dziga Vertov. México: Era, 1971

TAL, Tzvi. Pantallas y Revolución. Buenos Aires: Lumiere, 2005

VERTOV, Dziga. Artículos, Proyetos y Diários de Trabajo. Buenos Aires: De la Flor, 1974 